\title{
Twenty Years of Middle School STEM Camps at UW-La Crosse
}

\author{
Susan E. Kelly ${ }^{1}$ and Basudeb Bhattacharyya ${ }^{2}$ \\ ${ }^{1}$ Department of Mathematics and Statistics \\ ${ }^{2}$ Department of Chemistry and Biochemistry \\ University of Wisconsin-La Crosse, La Crosse, Wisconsin, USA
}

\begin{abstract}
UW-La Crosse has offered middle school science and mathematics camps for twenty years through a partnership of its College of Science and Health and its Office of Continuing Education and Extension. This paper will give information on the history of the program, overall camp design, specific examples of workshop offerings, and details on the administration of the programs.
\end{abstract}

\section{History of the Camps}

UW-La Crosse (UWL) first offered the Girls in Science, a middle school STEM camp, in 1998, as a partnership with the Wisconsin Center for Academically Talented Youth (WCATY). We offered the program to girls who took part in gifted programs and promoted it as a program offering advanced level workshops designed to keep girls engaged in mathematics and science. The following year, enrollment declined, and WCATY cancelled the event. In 2000, a group of faculty and staff from the UWL College of Science and Health and the Office of Continuing Education and Extension (CEE) decided to offer the program again. UWL expanded the camp to serve more students by inviting girls who participated in various gifted programs or submitted a letter of recommendation from a teacher. We stopped advertising the workshops as advanced level, but instead promoted workshops taught by university faculty and staff that provided hands-on learning experiences designed to excite students about science and mathematics [Nagel, D.]. Eventually the camps were open to all girls who were interested in attending, and in 2011, a similar program, Boys Science Exploration, was started for middle school boys.

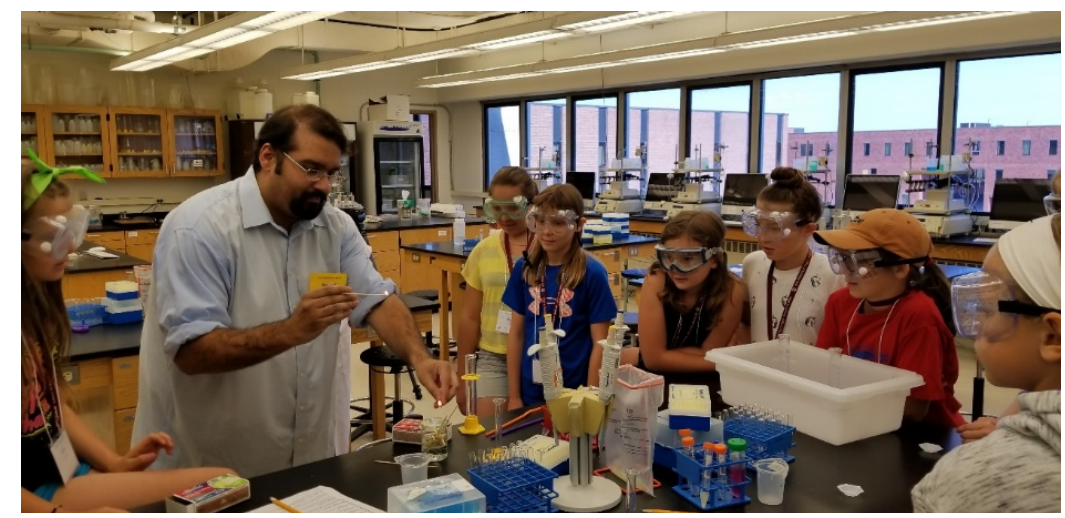

Fig. 1. Basudeb Bhattacharyya demonstrates a property of carbon dioxide.

${ }^{1}$ A WSGC grant partially funded the 2018 UWL STEM camps. Susan Kelly taught in the first program in 1998, and has served as a science director to the programs beginning in the camp's second year. She has continued to teach in the program at various times.

${ }^{2}$ Basudeb Bhattacharyya has taught in the program for three years and has developed three different workshops for the camps. 
While the principal aim of the camps has been to keep students interested in science, an underlining goal has been to show that science belongs to everyone and is not only for people who show a strength in the field at a young age. The hope is that these camps will attract students who may someday choose to work in STEM fields as well as reach students who may not become scientists but will foster a lifelong appreciation and interest in how science can enrich their lives. As a result, each year's planning includes examining ways to increase the diversity of camp participants.

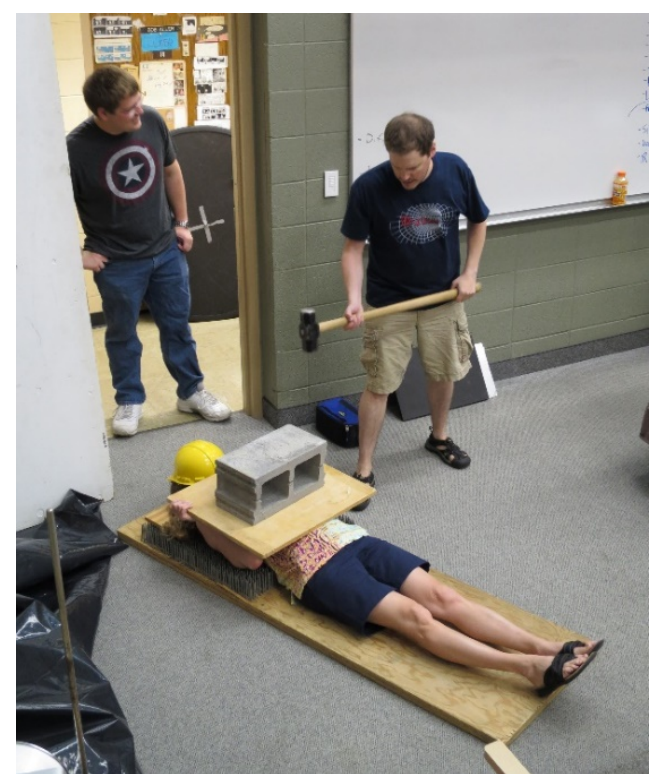

Fig. 2. Seth King with hammer and Susan Kelly on bed of nails demonstrate properties of physics for students during a large group presentation.

\section{Camp Design}

The boys' and girls' camps run as two separate programs that run concurrently over one weekend every June. Each of the two programs accepts a maximum of forty-eight students. Students arrive on Saturday and begin the program in the early afternoon. They stay overnight in a campus residence hall and finish the program on Sunday. Typically, there is one large workshop or a guest speaker to address the full group. In addition, students take several hands-on smaller workshops. Each of the smaller workshops has a capacity of sixteen students. The science director arranges the small workshops in sets of three from similar disciplines, and students choose their favorites when they enroll. Depending on the exact format for a particular year, each student takes three or four of the hands-on workshops, and each workshop ranges in length between 1.5 and 2 hours in length. For example, the 2018 program began with families arriving in the late morning on Saturday. Families were welcomed, and the director provided basic camp instructions. The students then attended an hour-long feature presentation for all students from both the boys' and girls' camps, which began around noon. Next, each student took two 1.5-hour long hands-on workshops. The students then had dinner followed by recreational time and an evening in the residence hall. The next day, the students had breakfast in the residence hall and packed up their belongings. They then had a two-hour hands-on workshop followed by a pizza lunch. After lunch, campers had one final two-hour hands-on workshop before heading back to the residence halls, where their parents met them at about 2:30 PM. 


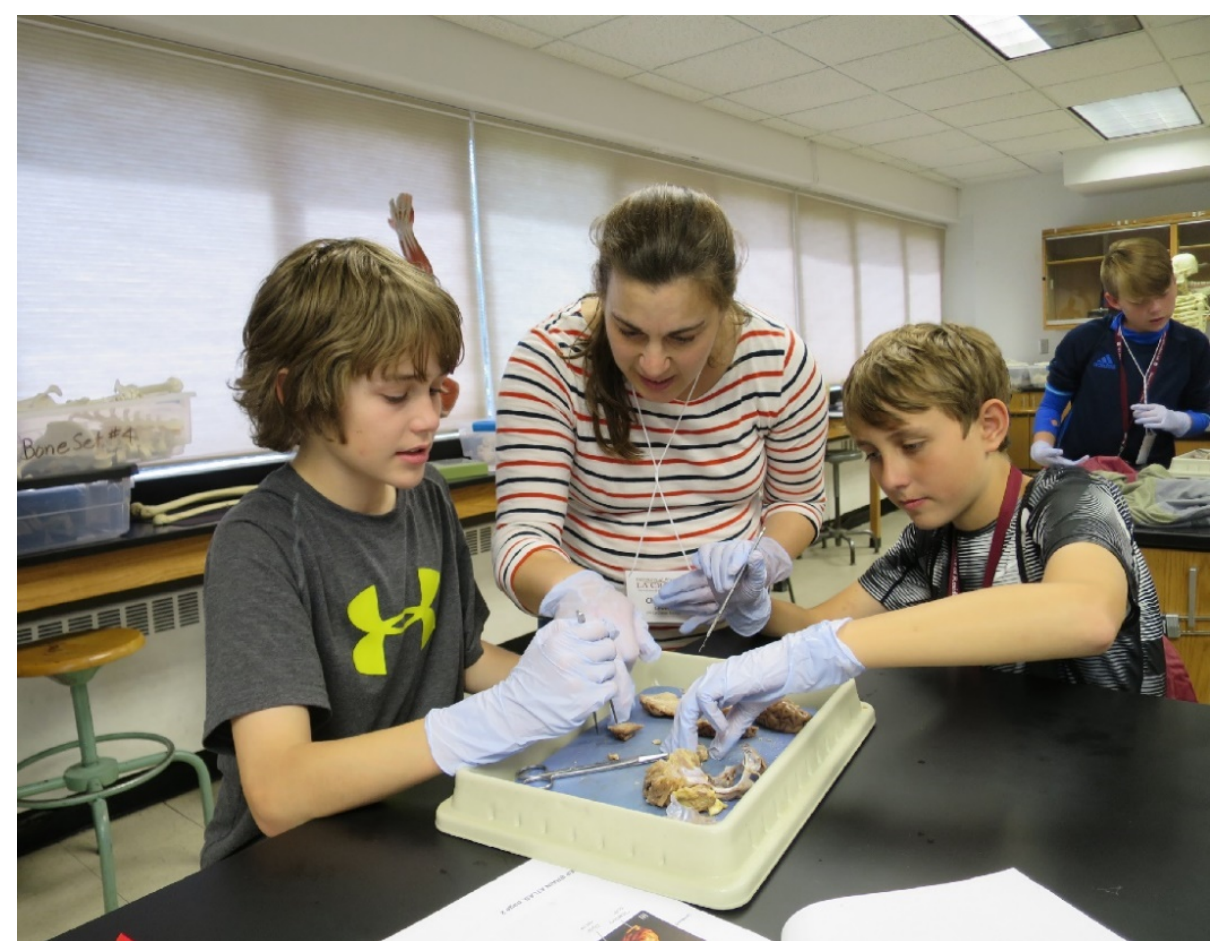

Fig. 3. Christine Schwartz assists boys in dissecting a sheep brain.

Camp organizers, faculty, and staff stress safety throughout the camps, since young students are on a campus designed for adults. Students are always chaperoned. Faculty and staff come to pick students up and take them back from their workshops. Resident assistants accompany students to and from their residence halls and dining areas. Faculty and staff take roll call several times during the camp to ensure that all students are accounted for while on campus.

\section{Workshops}

Typically, the camp includes one large workshop or speaker program. Often the chemistry or physics department will offer a one to two-hour program, which highlights many exciting demonstrations. The UWL River Studies program once offered a cruise of the Mississippi River, where students learned about the river and worked with water samples that faculty had gathered earlier. Guest speakers have included a chemist who discussed his research investigating alternative energy options at Argonne National Labs, a biologist who presented her research on how climate change affects the environment in the Arctic (Figure 4), and a NASA astronaut discussing his experiences in the space program and how new areas of space research would evolve (Figure 5).

Each year the camps offer smaller, hands-on workshops from a diverse collection of disciplines in the sciences. Each September, the camp director asks faculty from the College of Science and Health and some related departments outside the college if they have a workshop that they would like to teach. The director selects a combination of workshops that ensure an interesting assortment of options for students. Each year some of the workshops are ones instructors have taught several times, while others are new. 


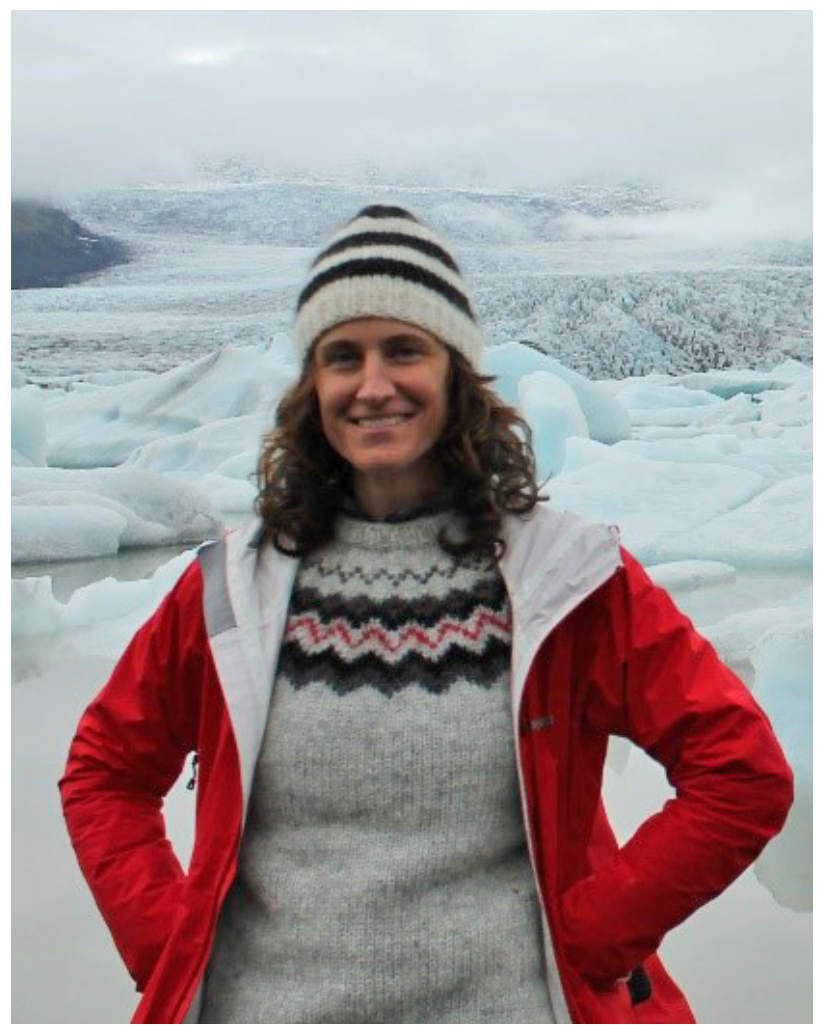

Fig. 4. Jill Welter explains her research in the Arctic during the 2018 program. Her talk was funded with a WSGC grant.

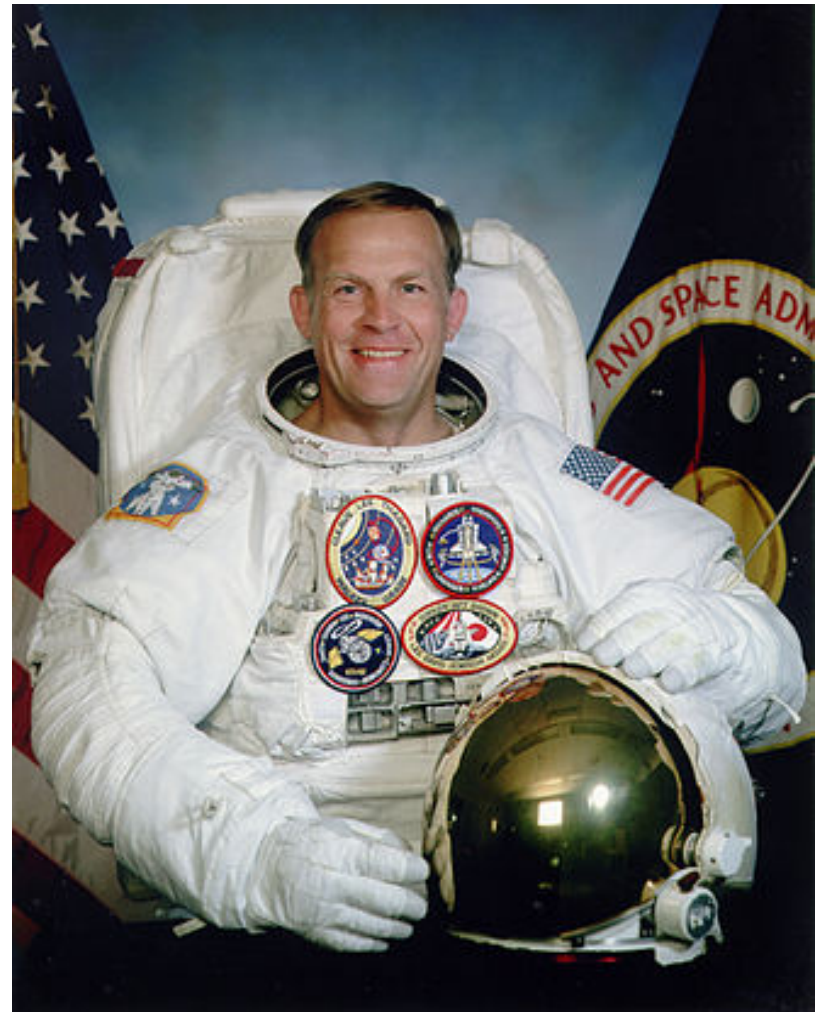

Fig. 5. Astronaut Mark Lee spoke at the 2015 camps. His talk was funded with a WSGC grant.

In 2018, the camps offered twelve hands-on workshops from the departments of Educational Studies, Archelogy/Anthropology, Computer Science, Mathematics/Statistics, Biology, Chemistry/Biochemistry, and Physics. In Educational Studies, students investigated how they could use engineering skills to help keep ice from melting. Workshops in Archelogy/Anthropology included one where students made and used stone tools and one where students learned about identifying a person from a small collection of bones (Figure 6). In Computer Science, students learned about how computers use computer languages to communicate across the internet. Mathematics workshops included one that taught how diseases spread and one where students played a game related to ideas about planes, planets, and universes in order to illustrate how mathematics is able to deal with abstract problems. The camps offered three Biology workshops in 2018. These workshops included a forensics-based activity where students used blood samples to solve a crime (Figure 8); students building a digestive system from household items (Figure 7); and lastly, dissecting sheep brains to learn about neuroscience (Figure 3). In Chemistry, students could take a workshop where they studied the chemical nature of carbon dioxide and saw how it affects the climate, environment, and people's lives (Figure 1). In a second Chemistry workshop, students learned about how light can be reflected, absorbed, and emitted from matter. Finally, in Physics, students learned about scientific principals governing roller coasters and built their own models. 


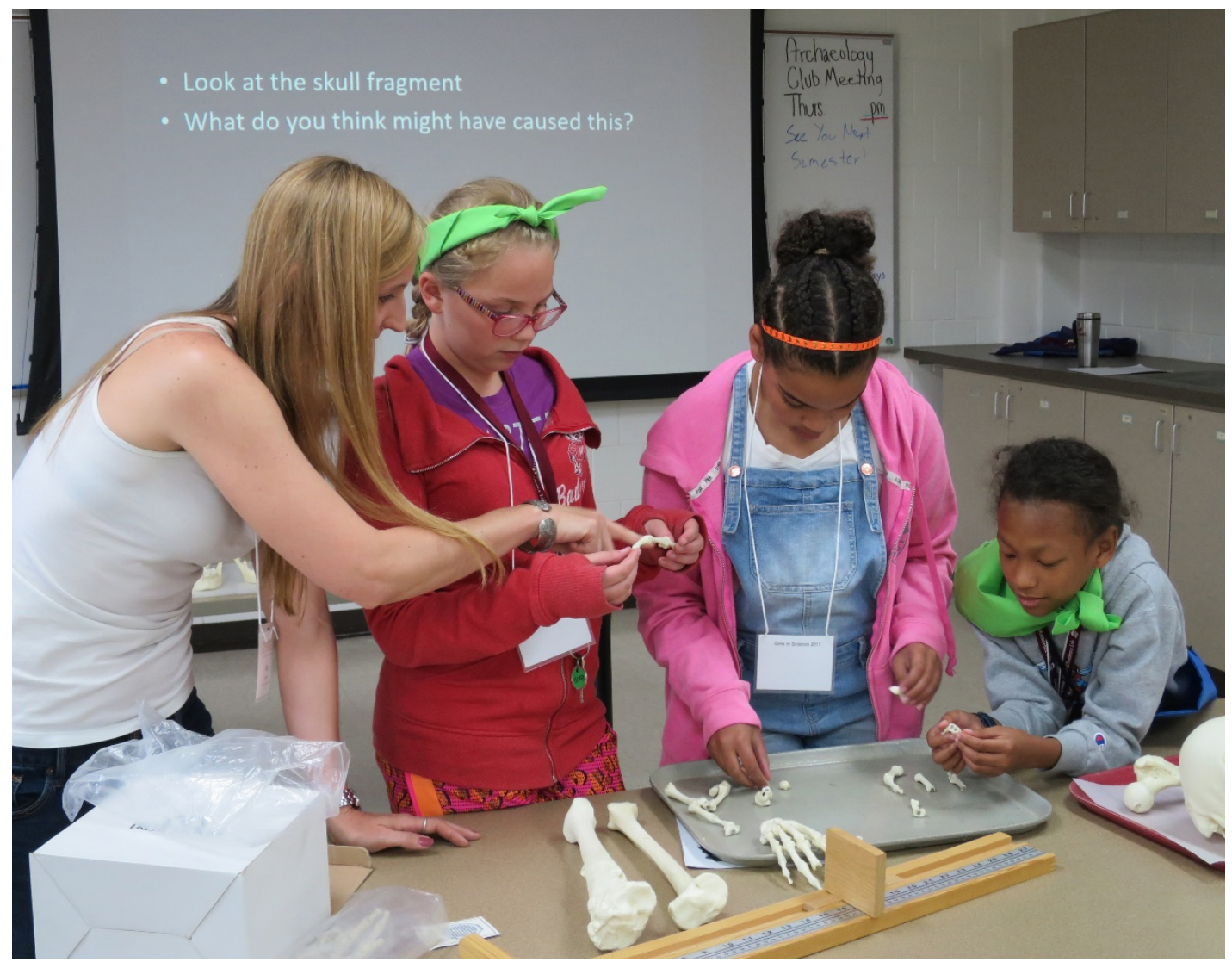

Fig. 6. Amy Nicodemus mentors girls about what one can learn from bones.

University faculty and staff are often unsure what to expect from a middle school age class the first time they teach in the program. They find it helpful to talk to people who have taught in the program before to help them plan activities. Many find that the boys' groups exhaust them a bit more than the girls' groups. Most instructors enjoy the energy and curiosity of the students and teach in the program often. Some of the instructors have taught in the program for ten or more years.

\section{Administration of Program}

Planning for each camp typically begins shortly after the last camp is completed. Over the summer, budget and camp assessments are gathered, and a general camp structure for the next year is developed. Camp enrollment targets are set to help with budgets and determining tuition costs for the following year. For the past two years, we have been able to offer special scholarships that we give to local schools. At these schools, middle school teachers choose students to attend at significantly lower costs.

In September, the director sends out a request to find faculty and staff interested in teaching in the program. By October or early November, the director selects all instructors. Instructors submit a title and paragraph description by December for the web pages and printed fliers. The director finalizes all grant funds and CEE finalizes the budget and tuition costs. In January and February, the website and fliers are completed and printed, and advertising begins. 


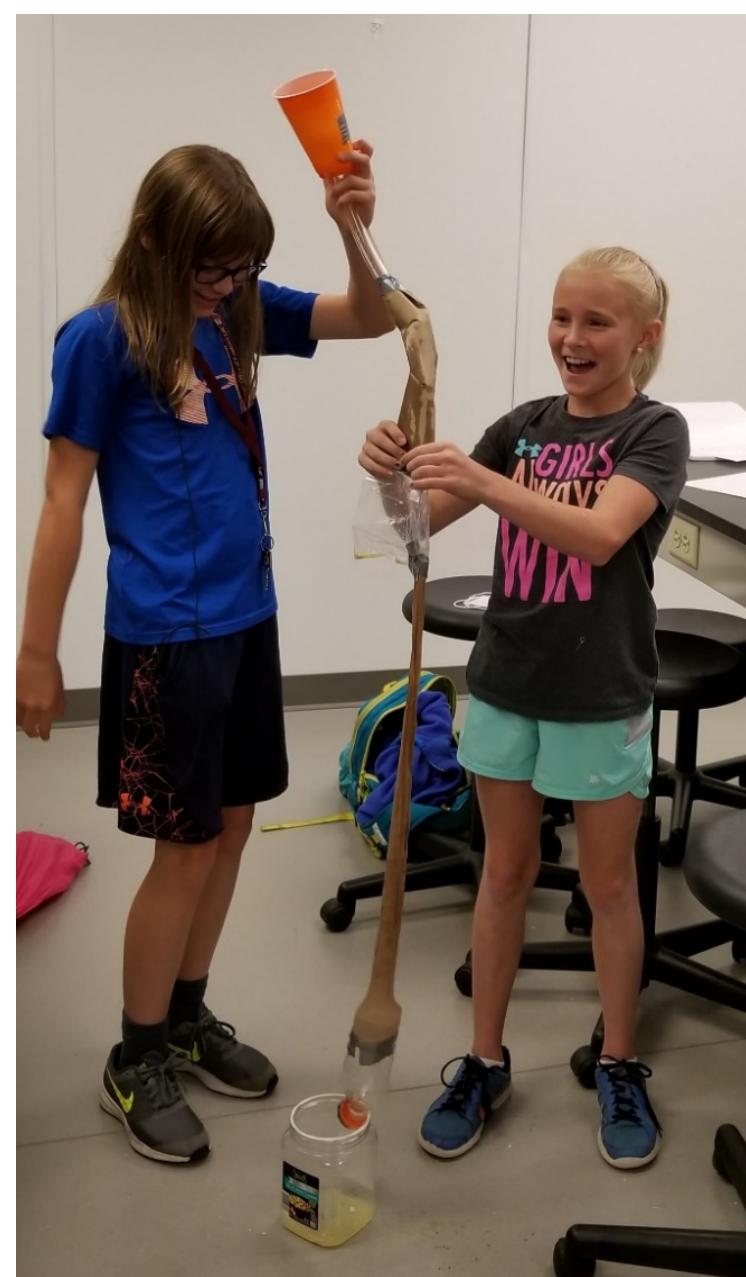

Fig. 7. Girls build a digestive system with household items in a workshop taught by Sumei Liu.

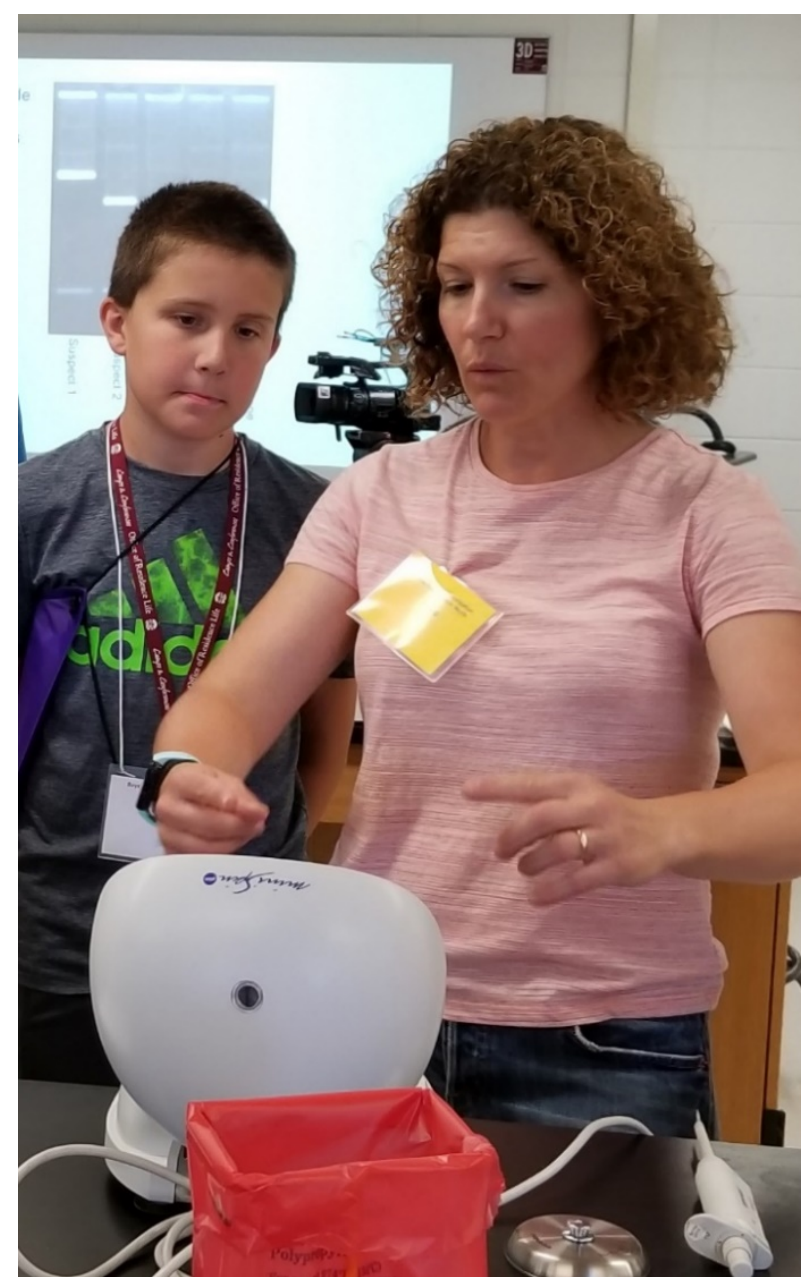

Fig. 8. Faye Ellis has taught students in the camps for multiple years about solving crimes using a blood sample.

In the spring, camp instructors submit names of their chosen student teaching assistant, and CEE chooses the resident assistants. Resident assistants had originally been university students, but over the past six to nine years, many have been alumni who have worked in the camps for multiple years. The CEE finalizes all necessary background checks for all people who work in the program.

Staff from CEE and the science director monitor enrollment and scholarships. CEE sets up needed reservations, camper insurance and food service needs for the program. During the program in June, staff from CEE and the science director monitor the program and address needs that arise.

\section{Looking to the Future}

Student and parent feedback has always been positive. Many students return for a second or third year. In addition, many siblings and students who have heard positive comments about the program from friends attend.

The greatest challenge to the program in recent years has been keeping the program affordable for families. The director, and past co-director, made a commitment early on to try to compensate instructors as fairly as possible for their time, while keeping the camp tuition as low as possible. 
Originally, camp tuition fully funded the camps. Years later, campus policies changed, and the camps were required to pay for services and facilities that the university used to provide at no cost to the camps. This caused camp costs to rise faster than cost of living. To offset these new and increased costs, the director has sought additional sources of revenue. Grant funding for ongoing programs can be challenging to secure, and each summer and autumn there is uncertainty on how budgets will work for the upcoming year's camps. Multi-year grant funding and community partnerships would help relieve some of this pressure, and the director is pursuing these options.

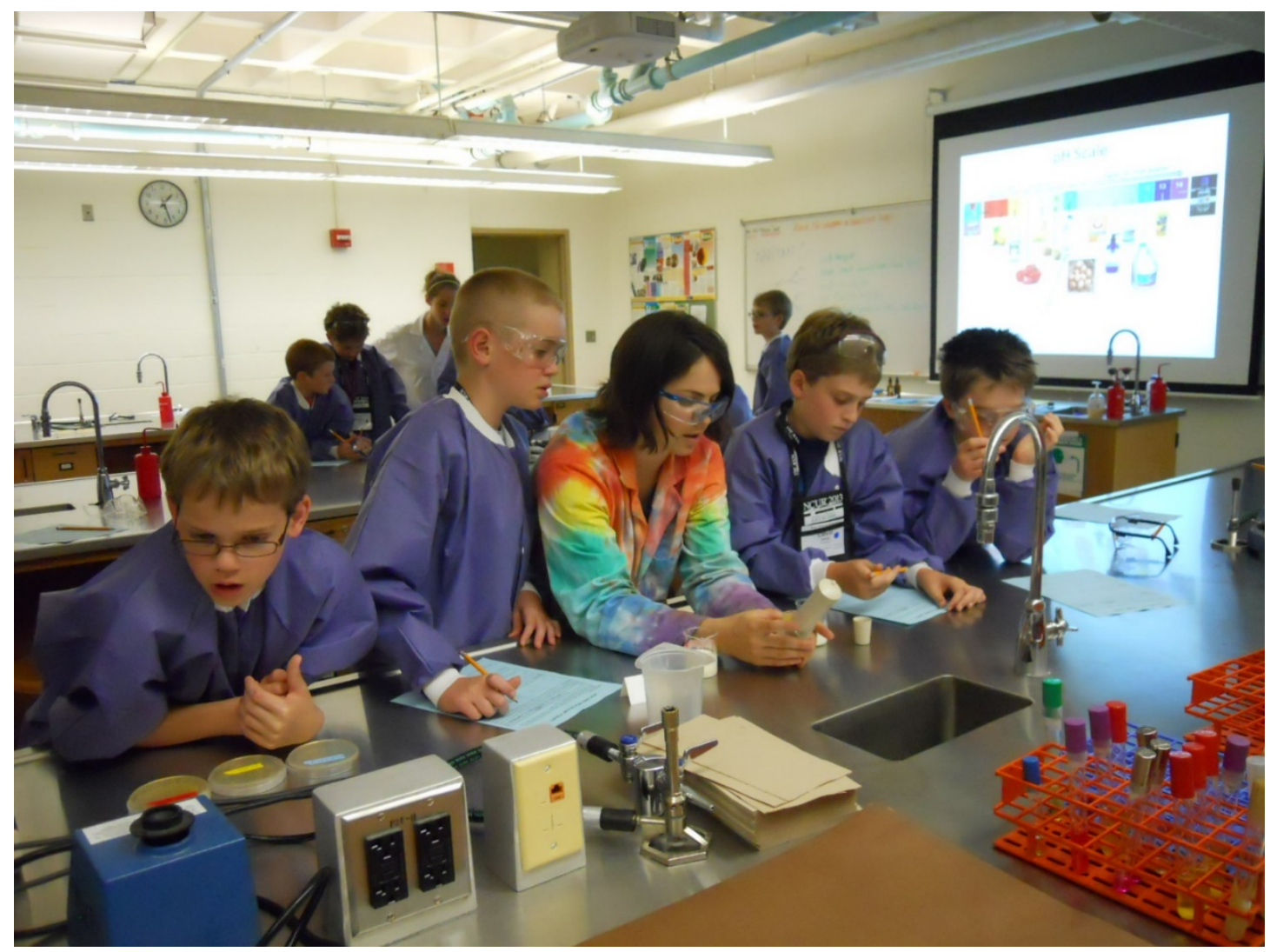

Fig. 9. Marisa Barbknecht instructs boys about the microbiology of food.

To relieve some of the pressure for the costs, UWL faculty and staff involved in the camps are giving thoughtful consideration of offering a two-day camp during the week that would not offer an over-night stay on campus. This would save on housing and food costs. We would likely lose some students who come from further distances, but hope to attract other students who could not come unless we lowered the cost. This would also allow both students and instructors to save their weekend for personal time.

The program has been successful for twenty years because of the dedication of many faculty, staff, alumni, and students of UWL. We hope that these camps continue to flourish for many years to come. Science is for everyone and this is one way that UWL shares science with the next generation. 


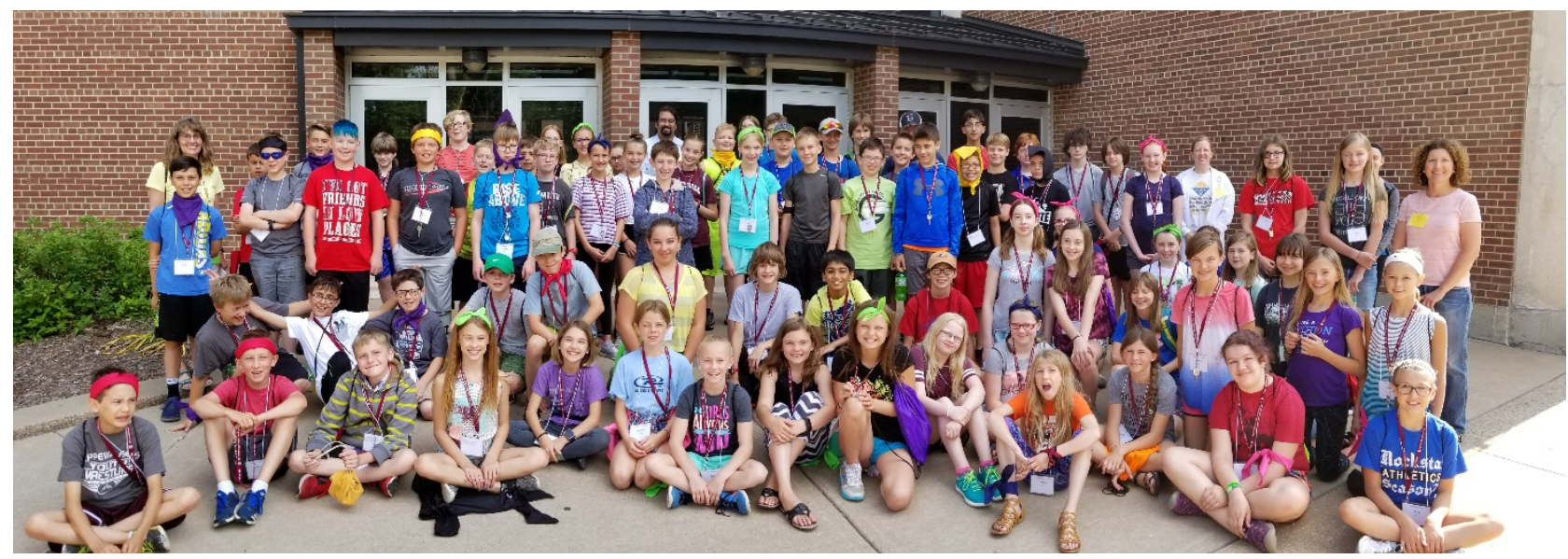

Fig. 10. 2018 campers along with some of the programs' instructors.

\section{Acknowledgments}

A grant from the Wisconsin Space Grant Consortium supported the guest speaker for the 2018 STEM camps. The Bosshard Family Fund, Gundersen Health System, and the Mississippi Archeology Center provided additional support. Several individuals also contributed to fund scholarships for the program. In addition, UWL also works with the Mississippi Valley Gifted and Talented Network on this program. Over the past twenty years, well over two-hundred faculty, staff, alumni, and students have dedicated time on these camps to make them successful!

\section{References}

[Nagel, D.] Mentors, Encouragement, Hands-on Learning Boost Girls' Interest in STEM Substantially, The Journal, March 13, 2018, https://thejournal.com/articles/2018/03/13/closingthe-stem-gap.aspx . 